\title{
Estimativa de disponibilidade hídrica para operação de uma central geradora hidrelétrica no Estado do Paraná
}

\section{Estimation of water availability for the operation of a hydroelectric generating plant in Paraná state}

DOI: $10.46814 /$ lajdv4n1-005

Recebimento dos originais: 01/12/2021

Aceitação para publicação: 20/01/2022

\author{
José Rafael de Oliveira \\ Geógrafo e mestrando em Geografia \\ Universidade Estadual do Centro-Oeste - UNICENTRO \\ Campus Cedeteg. Programa de Pós-Graduação em Geografia \\ Alameda Élio Antonio Dalla Vecchia, 838 - CEP 85040-167 - Guarapuava - PR \\ E-mail: raf.jr.oliv@gmail.com \\ Leandro Redin Vestena \\ Doutor em Engenharia Ambiental \\ Universidade Estadual do Centro-Oeste - UNICENTRO \\ Campus Cedeteg. Departamento de Geografia \\ Alameda Élio Antonio Dalla Vecchia, 838 - CEP 85040-167 - Guarapuava - PR \\ E-mail: lvestena@unicentro.br
}

\section{RESUMO}

O presente trabalho apresenta os resultados de um estudo para estimação da disponibilidade hídrica em um pequeno curso fluvial para a operação de uma central geradora hidrelétrica, no município de Santa Maria do Oeste, interior do estado do Paraná. A água é um recurso precioso para a vida humana. No Brasil, a energia elétrica é principalmente obtida em usinas hidrelétricas. A energia é gerada a partir do movimento de turbinas, que podem possuir diferentes tamanhos e potências. Apesar das centrais geradoras hidrelétricas serem empreendimentos com potencial gerador inferior a 5MW de energia um estudo da demanda hídrica é necessário para avaliação da viabilidade técnica e ambiental. Em razão da inexistência de dados de vazão na seção transversal do rio Santo Antônio onde a Central Geradora Hidrelétrica Santo Expedito está instalada a estimativa da disponibilidade hídrica deu-se a partir da extrapolação de dados hidrológicos regionais de séries históricas de três estações próximas. Os resultados indicaram uma vazão média diária estimada na seção transversal fluvial do rio Santo Antônio de $3,37 \mathrm{~m}$ 3/s. A vazão ecológica no curso fluvial deve ser de no mínimo 87 1/s. A capacidade instalada de geração de energia na Central Geradora Hidrelétrica Santo Expedito é de 3,7 m³/s em potência máxima. A disponibilidade hídrica indica haver vazão para operação da usina em sessenta e cinco por cento do tempo.

Palavras-chave: Outorga de recursos hídricos, Regionalização de vazão, Vazão ecológica, Meio ambiente.

\section{ABSTRACT}

This paper presents the results of a study to estimate the water availability in a small river course for the operation of a hydroelectric generating plant, in the municipality of Santa Maria do Oeste countryside of the state of Paraná. Water is a precious resource for human life. In Brazil, electrical 
energy is mainly obtained from hydroelectric power plants. The energy is generated from the movement of turbines, which can have different sizes and power outputs. Although hydroelectric power plants are enterprises with generating potential lower than 5MW of energy, a study of the hydroelectric demand is necessary for the evaluation of technical and environmental feasibility. Due to the inexistence of flow data on the cross-section of the Santo Antônio River where the Santo Expedito Hydroelectric Power Plant is installed, the estimate of water availability was based on the extrapolation of regional hydrological data from the historical series of three nearby stations. The results indicated an estimated average daily flow of $3.37 \mathrm{~m} / \mathrm{s}$ in the river cross section of the Santo Antônio River. The ecological flow rate in the river course should be at least 87 1/s. The availability of water indicates that there is a flow to operate the power plant sixty-five percent of the time.

Keywords: Water resources allocation, Regionalization of water flow, Ecological flow, Environment.

\section{INTRODUÇÃO}

A manutenção da vida no planeta depende exclusivamente da água nas suas diversas dimensões. A sua existência ou ausência é o que determina a ocupação dos lugares, cria culturas, estabelece hábitos, além de influenciar no futuro das gerações. Este recurso natural passou a ser usado em massa pela sociedade em seus diversos usos, em especial, para suprir a necessidade energética das gerações atuais, a partir de imponentes construções hidrelétricas (BACCI; PATACA, 2008).

As primeiras usinas hidrelétricas brasileiras surgiram nos finais do século XIX, onde buscavam responder às demandas impostas pelo setor industrial. Naquele momento o projeto e a construção desses empreendimentos constituíram-se em grandes experimentações, levando às inúmeras inovações técnicas, necessárias para se adaptar às características físicas do território brasileiro. Dessa forma, havia-se uma necessidade de leis e normas que estabelecessem regras para as construções desses empreendimentos, uma vez que eles podem causar inúmeros problemas ambientais (GERIBELLO, 2015).

Nesse cenário, no Brasil, a década de 1980 ficou marcada como a década do meio ambiente pela adoção de um conjunto de políticas ambientais, com objetivos voltados a sua proteção, em especial, a Lei da Política Nacional do Meio Ambiente (Lei $\mathrm{n}^{\circ}$ 6.938/810) e em seguida, pela Constituição Federal de 1988. O poder público passou então a assegurar o cumprimento dos princípios ambientais, na perspectiva da defesa, conservação e da preservação do meio ambiente como requisito essencial para garantir a vida da população e de formular políticas públicas de sustentabilidade. Deste modo, prevendo medidas de controle ambiental para empreendimentos ou atividades utilizadoras de recursos naturais, ou potencialmente poluidoras, que possam levar à degradação do ambiente (CAMPOS; SILVA, 2012).

Segundo a Lei $n^{\circ}$ 6.938/810, que diz respeito sobre a Política Nacional do Meio Ambiente, os proprietários de imóveis que contenham empreendimentos que possam levar a danos ambientais, como 
é o caso de usinas hidrelétricas, foco do presente estudo devem realizar Estudo de Impacto Ambiental / Relatório de Impacto Ambiental (EIA/RIMA). Devem permitir a inspeção e a fiscalização das suas propriedades, bem como, prestar informações necessárias sobre relatórios e renovações de licença. As licenças ambientais são as que permitem a instalação e a manutenção dessas atividades, sendo estabelecidas em três etapas: licença prévia, de instalação e de operação.

Conforme os artigos 19 do Decreto 99.247/90 e 8 da Resolução 237/97 do CONAMA três licenças ambientais são necessárias: a licença prévia (LP) - fase preparatória do planejamento, no qual alguns requisitos devem ser atendidos, atestando a viabilidade ambiental e os condicionantes a serem atendidos nas duas próximas fases de efetivação, respeitando os planos municipais, estaduais ou federais do uso do solo; a licença de instalação (LI) - refere ao momento da instalação do empreendimento ou atividade de acordo com as especificações que foram impostas na primeira etapa, incluindo todas as medidas de controle ambiental, as regras e adequações que devem serem efetivadas durante a utilização e após o seu encerramento; e a licença de operação (LO) - a última parte a ser executada para que se tenha a efetiva liberação das atividades nesses empreendimentos.

Todas as verificações e medidas de controle ambiental devem ser obedecidas, para que o meio ambiente não venha a ser impactado negativamente, sob pena de suspensão ou cancelamento da licença. A sua renovação é concedida após a execução de uma nova vistoria pelos órgãos ambientais responsáveis de cada Estado brasileiro e o tempo varia de acordo com a localidade, potencial poluidor e o tamanho do empreendimento. Essas três etapas, são de grande importância para o licenciamento ambiental brasileiro, porque são exigidos desde o projeto inicial de construção dos empreendimentos, até depois de finalizados.

Todo o empreendimento relacionado à produção de energia elétrica causa impacto do ponto de vista social e no meio ambiente local independentemente de serem usinas hidrelétricas de grande ou de pequeno porte. Esses impactos exigiram a implantação de uma legislação mais sólida e impulsionaram o aparecimento de novas formas de geração de energia como é o caso das CGHs (Centrais Geradoras Hidrelétricas) e PCHs (Pequenas Centrais Hidrelétricas).

De acordo com a ABRAPCH (Associação Brasileira de PCHs e CGHs) as CGHS são usinas com potência máxima de 0 até 5 megawatts $(\mathrm{MW})$ e as $\mathrm{PCHs}$ com potência entre 5 e $50 \mathrm{MW}$. Com estruturas reduzidas e mais baratas para se construir, de modo geral, causam pequenos danos ambientais à fauna e à flora, não alagando grandes extensões de áreas, pois podem ser construídas em rios com vazões menores (ABRAPCH, 2021).

Fernandes (2019), define as CGHs como mini usinas hidrelétricas em propriedades privadas que aproveitam apenas a queda livre natural do rio, sem formação de reservatório e com potência de geração de $1 \mathrm{MW}$ a $5 \mathrm{MW}$, tendo quatro funções principais em sua estrutura: captação, adução, geração 
e restituição. A captação segundo Fernandes (2019) é constituída por um barramento, que tem a funcionalidade de garantir a tomada d'água para o desvio deste líquido através de um canal ou conduto de adução. A geração de energia advém do movimento causado pela água na casa de força, pela turbina, sendo que a restituição se trata da devolução da vazão novamente ao rio.

O funcionamento desse empreendimento é liberado após cumprimento das três etapas da licença ambiental. Contudo, CGHs precisam renovar as suas licenças de operações de acordo com as regras, prazos e legislações dos órgãos ambientais responsáveis. Nessa etapa, a outorga de água também será renovada, tendo que efetuar os requisitos solicitados no licenciamento. Segundo a Agência Nacional de Águas e Saneamento Básico (2021) uma outorga de água consiste no direito de uso e no controle quantitativo e qualitativo dos recursos hídricos em prazo determinado, que são utilizados para diversas formas como: irrigação, abastecimento urbano, industrial e em especial para a geração de energia hidroelétrica.

$\mathrm{Na}$ definição da outorga de uso de um recurso hídrico para geração de energia é necessário também garantir a vazão ecológica no corpo hídrico. A vazão ecológica ou vazão mínima residual, trata-se de um volume mínimo que se deve ser mantido no trecho do rio no barramento ou na retirada da água (VESTENA et al., 2012). Para definir esses valores no Brasil são necessários dados de vazões, porém, nem todas essas localidades possuem estações fluviométricas, visto que, o Brasil possui enorme extensão territorial e dificuldades para instalação e operação de estações, principalmente em regiões mais distanciadas dos grandes centros populacionais.

$\mathrm{Na}$ falta desses dados, uma das alternativas é a transferência de informações hidrológicas de um local próximo e que contenha características ambientais similares. Esse processo é chamado de regionalização hidrológica, segundo Tucci (1991), tratando-se de um conjunto de procedimentos metodológicos que visa a estimativa de variáveis hidrológicas em localidades com dados insuficientes. Esse método facilita que centrais geradoras hidrelétricas que não possuam equipamentos para coletas de vazões deem continuidade no seu processo de outorga de água e renovação da licença ambiental do empreendimento.

Nesse contexto, o objetivo do presente estudo foi realizar uma estimativa de disponibilidade hídrica para operação de uma Central Geradora Hidrelétrica, no caso a CGH Santo Expedito, localizada no município de Santa Maria do Oeste, região central do Estado do Paraná, para subsidiar solicitação de renovação da licença ambiental de operação. 


\section{MATERIAIS E MÉTODOS}

\section{1 ÁREA DE ESTUDO}

A CGH Santo Expedito está localizada no município de Santa Maria do Oeste na região centrosul do Estado do Paraná, situa-se nas coordenadas geográficas 2458’02,6” latitude Sul e 5152’41,49” longitude Oeste (Figura 1 e 2). A área drenada na seção transversal fluvial do rio Santo Antônio, na CGH Santo Expedito é de 102,31 km² (Figura 3) e engloba toda a extensão urbana do município de Santa Maria do Oeste até a divisa com o município de Pitanga-PR. A área de drenada na CGH Santo Expedito é parte integrante da bacia hidrográfica do Rio Piquiri pertencente a bacia do Rio Paraná.

Figura 1: Localização da CGH Santo Expedito.

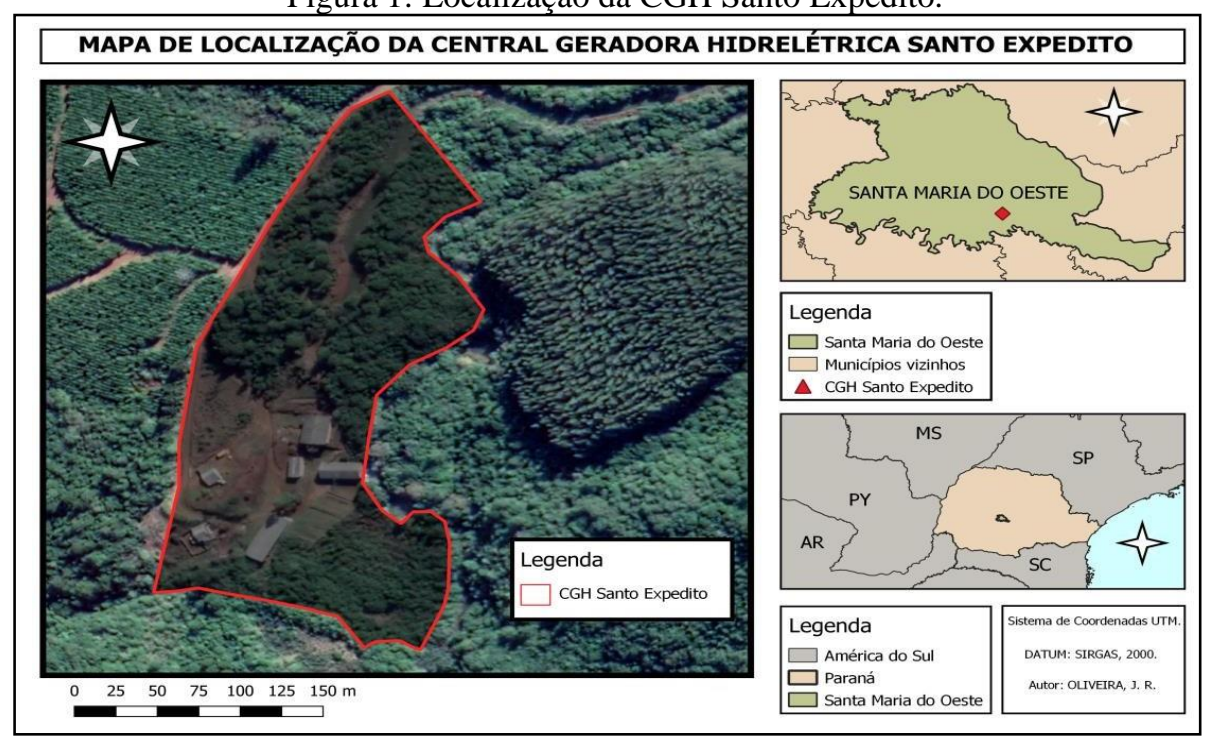

Fonte: Autores, 2021.

Figura 2: CGH Santo Expedito.

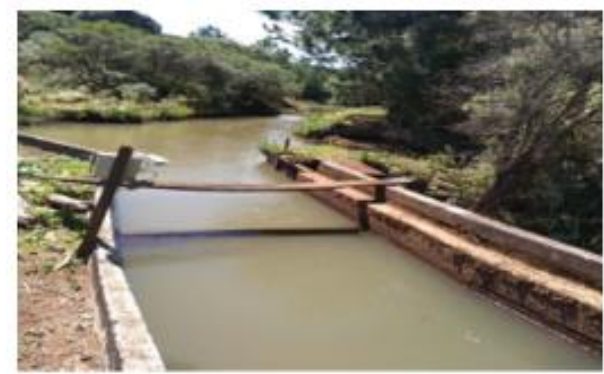

(a) Canal do rio Santo Antônio a jusante

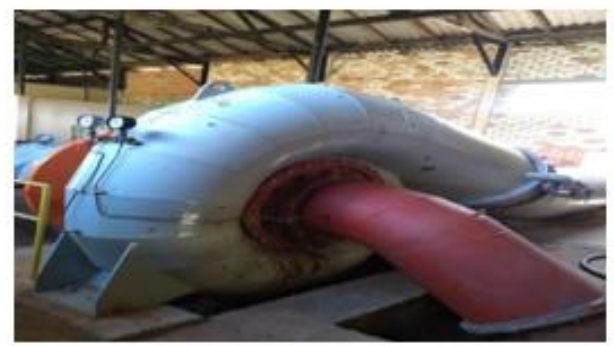

(c) Gerador

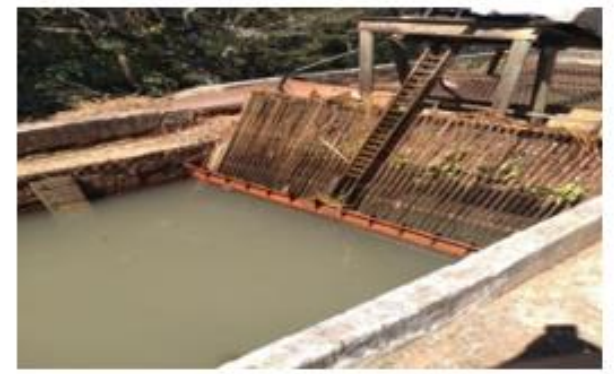

(b) Reservatório e barragem

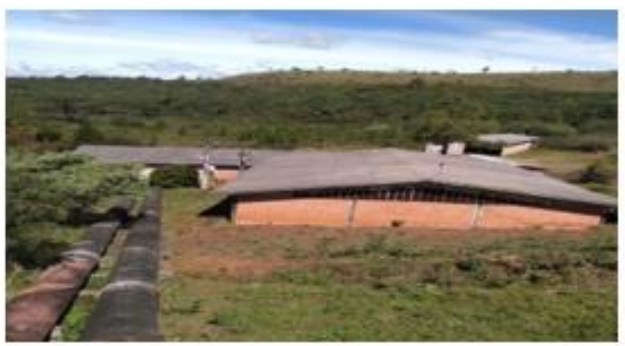

(d) Casa de máquinas

Fotografias: GOLDONI, 2021. 
Figura 3: Área de drenagem da CGH Santo Expedito.

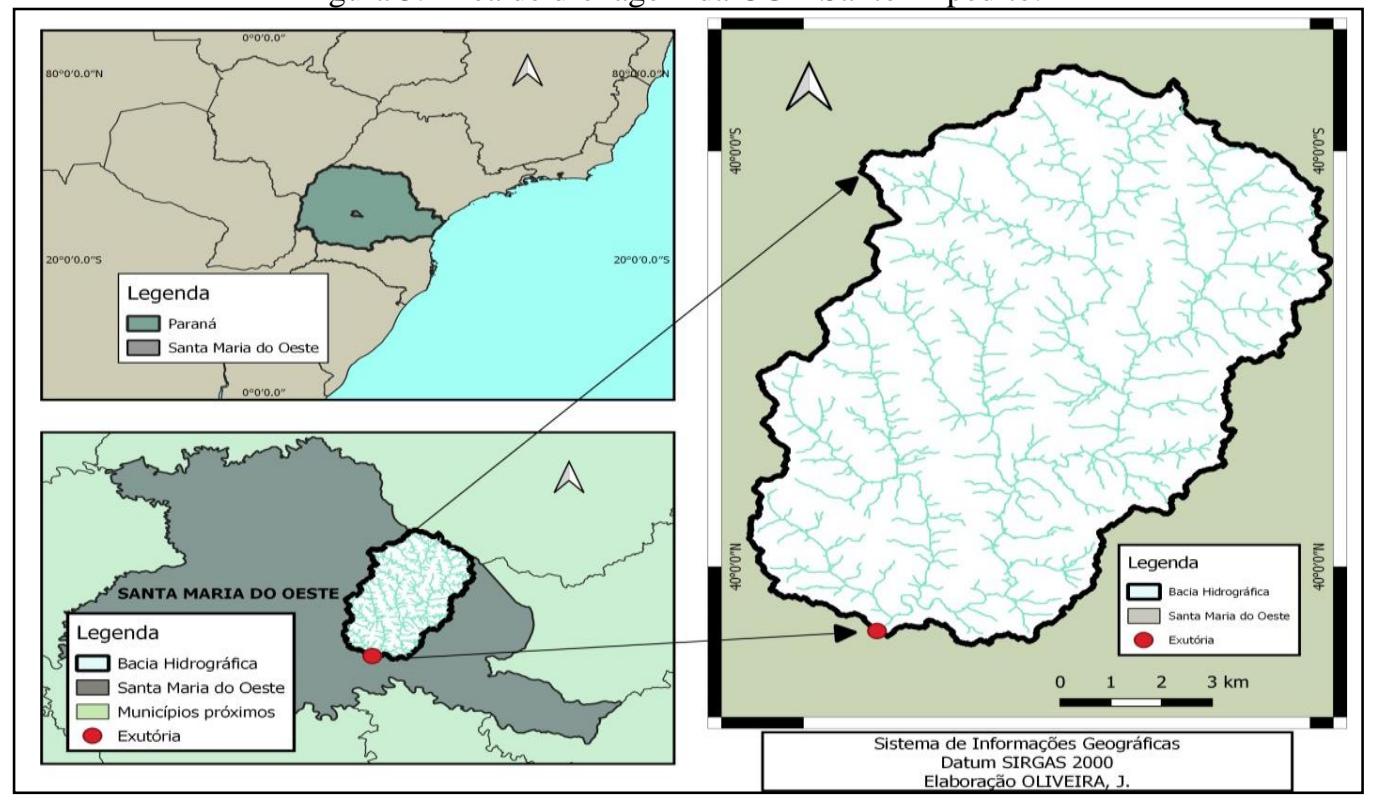

Fonte: Autores, 2020.

Segundo o IBGE (2010), o município de Santa Maria do Oeste possui uma área total de $845,53 \mathrm{~km}^{2}$ e $97 \%$ do seu território está inserido na bacia hidrográfica do rio Piquiri, de acordo com Instituto Água e Terra (2010). As suas fronteiras limitam-se com os municípios de Pitanga, Palmital, Goioxim, Campina do Simão, Boa Ventura do São Roque e Turvo, bem como, possui uma população estimada pelo IBGE (2020) de 9.410 habitantes.

\subsection{PROCEDIMENTOS METODOLÓGICOS}

Em razão de na seção transversal fluvial do rio Santo Antônio na CGH Santo Expedito não dispor de uma estação fluviométrica optou-se por usar dados de vazões de estações fluviométricas localizadas em pequenas bacias hidrográficas próximas disponibilizados pelo Instituto Água e Terra (IAT).

Foram identificadas treze estações fluviométricas próximas a CGH Santo Expedito, num raio de $80 \mathrm{~km}^{2}$, porém, apenas cinco delas estão em funcionamento, as estações: Guampará, Ponte Leoncio Primo, ETA Guarapuava, Posto Carriel, e Tereza Cristina (Quadro 1). Das cinco estações fluviométricas com dados de vazão disponíveis três foram escolhidas para estimação da vazão média específica, seguindo os critérios: possuir dados de vazões monitorados de um período de no mínimo 30 anos; e apresentar cobertura da terra semelhantes à da área de drenagem da CGH Santo expedito (Figura 4). As estações fluviométricas escolhidas foram: Guampará, Ponte Leoncio Primo e ETA Guarapuava (Quadro 2). 
Quadro 1: Estações fluviométricas próximas a área de estudo.

\begin{tabular}{|l|l|l|l|l|l|}
\hline Nome da Estação & Código & Instalação & Extinção & Sede & $\begin{array}{l}\text { Distância } \\
\text { até a CGH } \\
\text { (km) }\end{array}$ \\
\hline ETA PITANGA & 64634000 & $16 / 02 / 2002$ & 2013 & Pitanga & 25 \\
\hline IBEMA CACHOEIRA & 64630500 & $07 / 11 / 2000$ & $31 / 12 / 2009$ & Turvo & 44 \\
\hline GUAMPARÁ & 64764000 & $01 / 06 / 1984$ & Em funcionamento & Palmital & 44 \\
\hline $\begin{array}{l}\text { IBEMA FAZENDA } \\
\text { BOA VISTA }\end{array}$ & 64630000 & $16 / 03 / 1957$ & $31 / 05 / 2003$ & Turvo & 46 \\
\hline $\begin{array}{l}\text { CARVENOSO EM } \\
\text { VAU DOS RIBEIROS }\end{array}$ & 65854500 & $30 / 03 / 2012$ & 2013 & Candói & 47 \\
\hline PITANGA LIMOEIRO & 64635000 & $01 / 09 / 1948$ & $31 / 12 / 1972$ & Pitanga & 40 \\
\hline $\begin{array}{l}\text { PONTE LEONCIO } \\
\text { PRIMO }\end{array}$ & 64773000 & $11 / 08 / 1978$ & Em funcionamento & Palmital & 55 \\
\hline $\begin{array}{l}\text { JUSANTE RIO DA } \\
\text { PRATA }\end{array}$ & 64764400 & $18 / 08 / 2004$ & $12 / 02 / 2012$ & Nova Laranjeiras & 58 \\
\hline SALTO DA ONÇA & 64637000 & $16 / 08 / 1962$ & $31 / 05 / 1980$ & Pitanga & 46 \\
\hline BARRA PRETA & 64638000 & $09 / 06 / 1956$ & $31 / 12 / 1958$ & Pitanga & 47 \\
\hline ETA GUARAPUAVA & 65809000 & $14 / 03 / 1985$ & Em funcionamento & Guarapuava & 62 \\
\hline PORTO CARRIEL & 64767000 & $27 / 05 / 1981$ & Em funcionamento & Laranjal & 75 \\
\hline TEREZA CRISTINA & 64625000 & $06 / 08 / 1956$ & Em funcionamento & Cândido de Abreu & 75 \\
\hline
\end{tabular}

Fonte: IAT, 2021.

Figura 4: Mapa de Localização das três estações escolhidas.

\section{LOCALIZAÇÃO DAS TRÊS ESTAÇõES FLUVIOMÉTRICAS UTILIZADAS NO ESTÁGIO.}

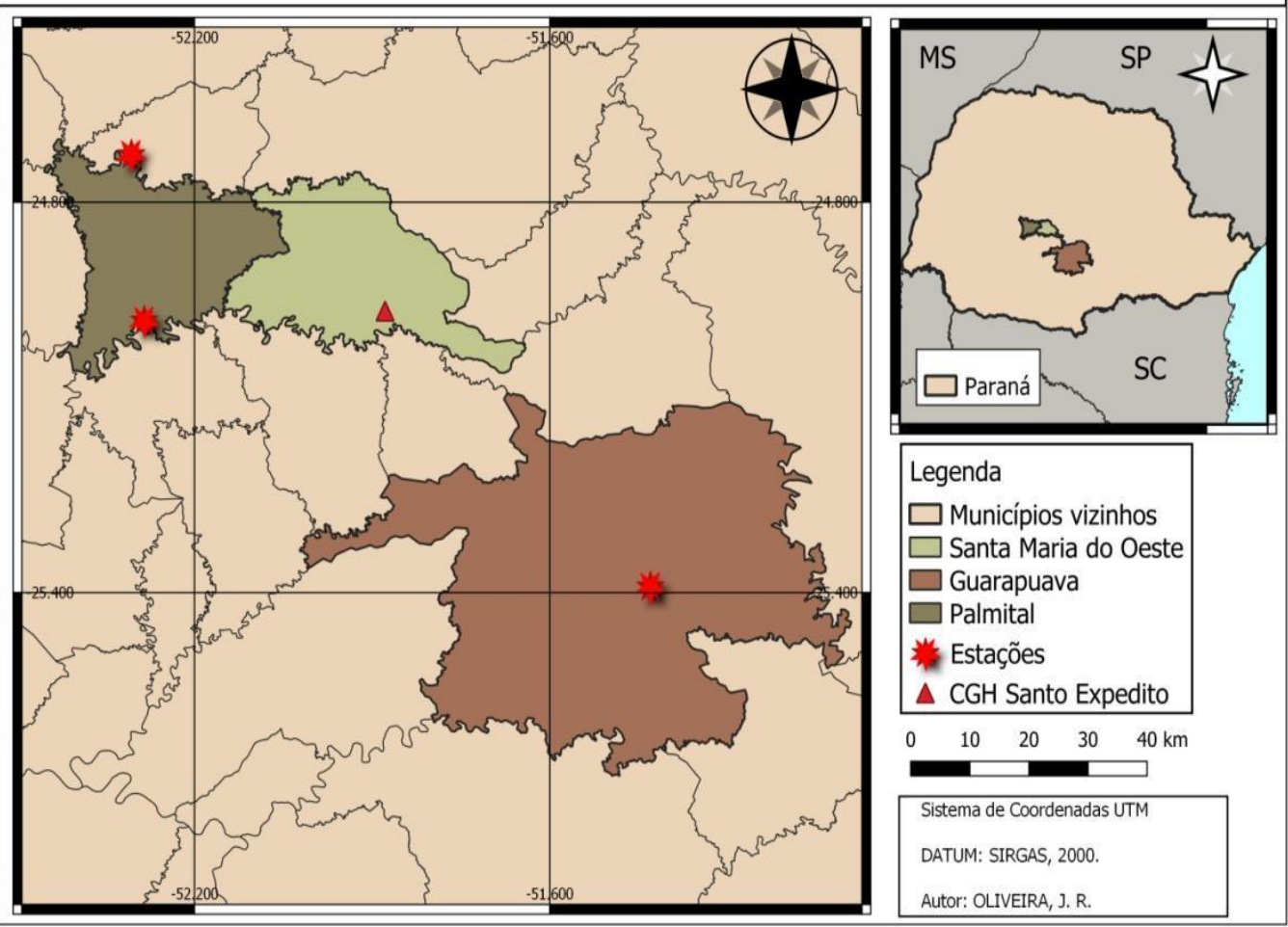

Fonte: Autores, 2020. 
Quadro 2: Estações Fluviométricas escolhidas.

\begin{tabular}{|c|c|c|c|c|c|c|c|}
\hline Estação & $\begin{array}{c}\text { Código } \\
\text { ANA }\end{array}$ & Município & Instalação & $\begin{array}{c}\text { Altitude } \\
(\mathbf{m})\end{array}$ & Rio & $\begin{array}{c}\text { Área } \\
\text { drenagem } \\
\left(\mathbf{k m}^{2}\right)\end{array}$ & $\begin{array}{c}\text { Série } \\
\text { temporal } \\
(\mathbf{a n o})\end{array}$ \\
\hline GUAMPARÁ & 64764000 & Palmital & $01 / 06 / 1984$ & 550 & Piquiri & 1703 & 35 \\
\hline $\begin{array}{c}\text { PONTE LEONCIO } \\
\text { PRIMO }\end{array}$ & 64773000 & Palmital & $11 / 08 / 1978$ & 480 & Cantu & 736 & 41 \\
\hline $\begin{array}{c}\text { ETA - } \\
\text { GUARAPUAVA }\end{array}$ & 65809000 & Guarapuava & $14 / 03 / 1985$ & 950 & Pedras & 315,77 & 34 \\
\hline
\end{tabular}

Fonte: ANA, 2021.

A vazão específica $\left(\mathrm{L} / \mathrm{s} / \mathrm{km}^{2}\right)$ em cada uma das três áreas de drenagem das estações fluviométricas escolhidas foram calculadas. Na sequência obteve-se a vazão específica média das três estações. Posteriormente, estimou-se extrapolando-se os dados de vazão média específica para a área drenada na secção transversal fluvial no rio Santo Antônio, na CGH Santo expedito.

O aplicativo SisCAH 1.0 (Sistema Computacional para Análise Hidrológica) foi utilizado para aquisição das curvas de permanências em cada uma das estações para obtenção das vazões de referência Q50, Q70, Q95, Q90, Q95 e Q7.10 e analise do regime hídrico.

\section{RESULTADOS}

Um comportamento similar dos regimes fluviais em ambas as estações foram observadas (Figura 5), apesar de haver diferenças nos volumes de vazões dentre as estações consideradas, evidenciados principalmente em períodos de picos e de vazões mínimas. A vazão média anual nas estações fluviométricas foram de $55,37 \mathrm{~m}^{3} / \mathrm{s}, 27,92 \mathrm{~m}^{3} / \mathrm{s}$ e $8,93 \mathrm{~m}^{3} / \mathrm{s}$ na Guampará, Ponte Leoncio Primo e ETA Guarapuava, respectivamente (Quadro 3).

Quadro 3: Vazão média anual e áreas de drenagem nas estações fluviométricas escolhidas.

\begin{tabular}{|c|c|c|c|}
\hline \multicolumn{4}{|l|}{ Estações selecionadas } \\
\hline Nome & Código & azão média anual & Área de drenagem \\
\hline Guampará & 64764000 & $55,37 \mathrm{~m}^{3} / \mathrm{s}$ & $1703,00 \mathrm{~km}^{2}$ \\
\hline Ponte Leoncio Primo & 64773000 & $27,92 \mathrm{~m}^{3} / \mathrm{s}$ & 736,00 km² $^{2}$ \\
\hline ETA Guarapuava & 65809000 & $8,93 \mathrm{~m}^{3} / \mathrm{s}$ & $315,77 \mathrm{~km}^{2}$ \\
\hline
\end{tabular}

Dados Brutos: ANA, 2021. 
Figura 5: Vazões diárias médias nas estações Guampará, Ponte Leoncio Primo e ETA Guarapuava.

$$
120
$$

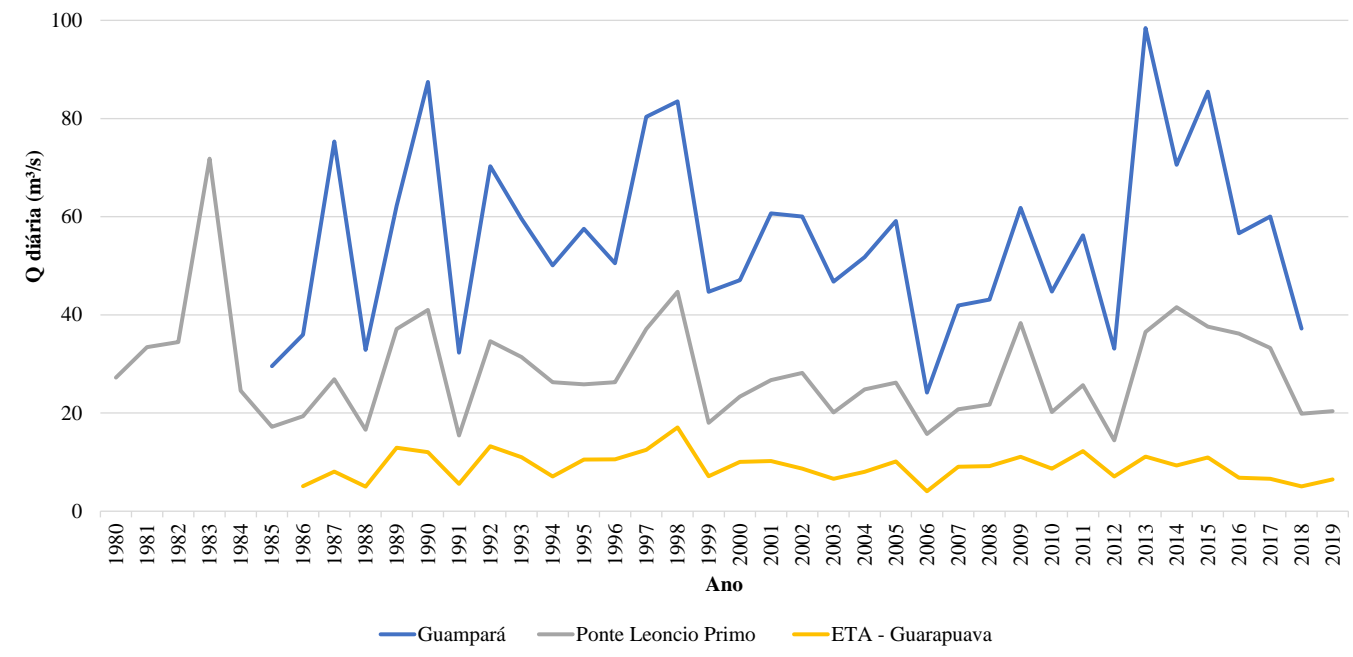

Dados Brutos: ANA, 2021.

A vazão específica média na série histórica em cada uma das bacias hidrográficas consideradas

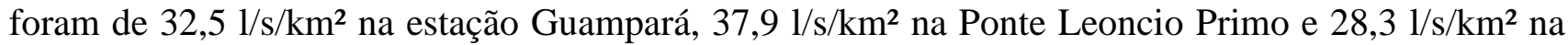
ETA Guarapuava. Os valores de vazão específica variaram de 28,3 a 37,9 1/s/km² apesar de ambas as áreas de drenagem estarem inseridas no Centro-Sul do Estado do Paraná e compartilharem de características climáticas e hidrológicas semelhantes.

A vazão média específica na área de drenagem das três estações fluviométricas consideradas foi de $32,91 / \mathrm{s} / \mathrm{km}^{2}$. O valor da vazão específica média ficou acima do valor constante no Atlas de Recursos Hídricos do Estado do Paraná de 1998 da Superintendência de Desenvolvimento de Recursos Hídricos e Saneamento Ambiental -SUDERHSA que indica uma vazão média específica na região para pequenas bacias hidrográficas inferiores a $5.000 \mathrm{~km}^{2}$ entre 22 e 24 1/s/km² (Quadro 4).

Com base nos valores de vazão específica disponíveis no Atlas de Recursos Hídricos do Estado do Paraná verificou-se que as vazões médias medidas nas estações Guampará e Ponte Leoncio Primo foram superiores (Quadro 4), enquanto a da ETA Guarapuava foi inferior. Um dos fatores que podem justificar essas diferenças é ela ser área de manancial de Guarapuava e a estação fluviométrica estar localizada próximo ao ponto de captação de água.

Após a aquisição da vazão específica média nas áreas de drenagem próximas a CGH Santo Expedito estimou-se por extrapolação uma vazão média diária de $3,37 \mathrm{~m} 3 / \mathrm{s}$, na seção transversal fluvial do rio Santo Antônio onde a CGH Santo Expedito está instalada. 
Quadro 4: Vazões especificas médias para pequenas bacias segundo o Mapa do IAT.

\begin{tabular}{|l|c|c|}
\hline \multicolumn{1}{|c|}{ Estações fluviométricas } & $\begin{array}{c}\text { Qemédia medida } \\
\left(1 / \mathrm{s}^{2} / \mathrm{km}^{2}\right)\end{array}$ & $\begin{array}{c}\text { Qemédia para pequenas bacias } \\
\text { hidrográficas segundo a } \\
\text { SUDERHSA (1998) } \\
\left(1 / \mathrm{s} / \mathrm{km}^{2}\right)\end{array}$ \\
\hline Guampará & 32,5 & 22 e 24 \\
\hline Ponte Leoncio Primo & 37,9 & 22 e 24 \\
\hline ETA Guarapuava & 28,3 & 30 e 32 \\
\hline CGH Santo Expedido (média) & $32,9 *$ & 22 e 24 \\
\hline
\end{tabular}

Nota: Qemédia é vazão específica média; *Dado estimado. Dados Brutos: IAT, 2021.

No quadro 5 tem-se a Q50, Q70, Q90 e Q95 nas três estações fluviométricas dada pela relação entre vazões versus permanência. Esses padrões de Q referem-se às vazões que são esperadas em um determinado tempo, como exemplo da Q90, onde é previsto que em 90\% do tempo ocorra um valor de vazão igual ou maior na seção fluvial, ou seja, em apenas $10 \%$ do tempo existe a probabilidade de ocorrer vazões menores (BELICO et al, 2013).

\begin{tabular}{|c|c|c|c|c|c|c|c|c|c|c|}
\hline \multirow{2}{*}{ Estação } & \multicolumn{2}{|c|}{ Q50 } & \multicolumn{2}{|c|}{ Q65 } & \multicolumn{2}{|c|}{ Q70 } & \multicolumn{2}{|c|}{ Q90 } & \multicolumn{2}{|c|}{ Q95 } \\
\hline & $\left(\mathrm{m}^{3} / \mathrm{s}\right)$ & $\left(1 / \mathrm{s} / \mathrm{km}^{2}\right)$ & $\left(\mathrm{m}^{3} / \mathrm{s}\right)$ & $\left(1 / \mathrm{s} / \mathrm{km}^{2}\right)$ & $\left(\mathrm{m}^{3} / \mathrm{s}\right)$ & $\left(1 / \mathrm{s} / \mathrm{km}^{2}\right)$ & $\left(\mathrm{m}^{3} / \mathrm{s}\right)$ & $\left(1 / \mathrm{s} / \mathrm{km}^{2}\right)$ & $\left(\mathrm{m}^{3} / \mathrm{s}\right)$ & $\left(1 / \mathrm{s} / \mathrm{km}^{2}\right)$ \\
\hline Guampará & 31,29 & 18,372 & 21,32 & 12,52 & 19,23 & 11,292 & 10,05 & 5,903 & 7,51 & 4,409 \\
\hline $\begin{array}{c}\text { Ponte } \\
\text { Leoncio } \\
\text { Primo } \\
\end{array}$ & 9,27 & 12,597 & 5,78 & 7,86 & 4,68 & 6,488 & 2,08 & 2,826 & 1,47 & 1,992 \\
\hline $\begin{array}{c}\text { ETA } \\
\text { Guarapuava }\end{array}$ & 5,19 & 16,446 & 3,80 & 12,02 & 3,41 & 10,835 & 1,95 & 6,169 & 1,44 & 4,569 \\
\hline $\begin{array}{l}\text { CGH Santo } \\
\text { Expedido }\end{array}$ & $1,62 *$ & 15,802 & 1,11 & 10,80 & $0,97^{*}$ & 9,483 & $0,51^{*}$ & 4,966 & $0,38^{*}$ & 3657 \\
\hline
\end{tabular}

Nota: * Dado estimado. Adaptado de SisCAH 1.0, 2021.

Em $95 \%$ do tempo ocorreram vazões maiores a $1 \mathrm{~m} 3 / \mathrm{s}$ nos canais fluviais das estações Guampará, Ponte Leoncio Primo e ETA Guarapuava. Isto evidencia que nessas localidades sempre será visível um escoamentosuperficial sobre os trechos dos rios, além de, indicar que a região é composta por rios perenes. De acordo com a resolução $n^{\circ}$ 141/2012 do IBAMA, rios perenes são aqueles cujos corpos de água possuem naturalmente escoamentos superficiais durante todo o período do ano.

A Q50, Q70, Q90 e Q95 estimada na seção transversal fluvial do rio Santo Antônio na CGH Santo Expedito é de $1,62 \mathrm{~m}^{3} / \mathrm{s}, 0,97 \mathrm{~m}^{3} / \mathrm{s}, 0,51 \mathrm{~m}^{3} / \mathrm{s}$ e $0,38 \mathrm{~m}^{3} / \mathrm{s}$, respectivamente.

Segundo Vestena et al (2012) a outorga de água concedida dar-se após estimar e garantir a vazão ecológica no corpo hídrico e que a legislação ambiental que estabelece as percentagens de vazões de referências para estimativa da vazão ecológica é uma política estadual. Para o Estado do Paraná a vazão ecológica é 50\% da vazão Q7.10 (PARANÁ, 1999 e BENETTI, LANNA e COBALCHINI, 
2003). Em vista disso, foram obtidos os valores de vazões ecológicas para às três estações e também na seção transversal fluvial CGH Santo Expedito (Quadro 6).

\begin{tabular}{|c|c|c|}
\multicolumn{2}{|c|}{ Quadro 6: Vazão Q7.10 de referência a vazão ecológica. } \\
\begin{tabular}{|c|c|c|}
\hline Estações e CGH & Q7.10 $\left(\mathrm{m}^{3} / \mathrm{s}\right)$ & Q7.10 $\left(1 / \mathrm{s}_{\mathrm{km}}\right)$ \\
\hline Guampará & 3,918 & 2,301 \\
\hline Ponte Leoncio Primo & 0,519 & 0,705 \\
\hline ETA Guarapuava & 0,649 & 2,055 \\
\hline $\begin{array}{c}\text { CGH Santo Expedido - } \\
\text { Estimada }\end{array}$ & $0,173^{*}$ & $0,687^{*}$ \\
\hline
\end{tabular}
\end{tabular}

Nota: * Dado estimado. Fonte: Adaptado de SisCAH 1.0, 2021.

Na seção transversal CGH Santo Expedito a vazão ecológica estimada deve ser 871/s $(0,087$ $\mathrm{m}^{3} / \mathrm{s}$ ), ou seja, $50 \%$ da Q7.10.

A CGH Santo Expedito conta com energia gerada por duas turbinas uma de $300 \mathrm{CV}$ e uma outra de $450 \mathrm{CV}$ que demandam uma vazão de $3,7 \mathrm{~m}$ 3/s para geração de energia em potência máxima e pelo menos $30 \%$ dela $\left(1,11 \mathrm{~m}^{3} / \mathrm{s}\right)$ para mover as turbinas e gerar energia em potência mínima. De acordo como os dados estimados na seção transversal fluvial na CGH Santo Expedito (Quadro 5) podese afirmar que em $65 \%$ do tempo haverá água disponível para geração de energia.

\section{CONSIDERAÇÕES FINAIS}

A vazão diária média estimada para a seção transversal fluvial na CGH Santo Expedito foi de $3,37 \mathrm{~m}^{3} / \mathrm{s}$ e um valor para a vazão ecológica de $0,087 \mathrm{~m} 3 / \mathrm{s}$.

A disponibilidade hídrica indica que a Central Geradora Hidrelétrica Santo Expedito instalada demanda uma vazão mínima de $1,11 \mathrm{~m}^{3} / \mathrm{s}$ e operará em sesenta e cinco porcento do tempo.

Ressalta-se que os resultados são preliminares, em razão principalmente do regime hídrico ser impactado pelo uso e cobertura da terra na bacia hidrográfica e dos dados de vazão serem de extrapolação para o local. Recomenda-se a instalação de uma estação fluviométrica na seção transversal do rio Santo Antônio, onde está instalada a CGH São Expedito e o monitoramento da vazão em intervalo de tempo horário. Assim como a instalação de pluviómetros e pluviógrafos de maneira a se obter dados de representativos da chuva na área de drenagem, para que uma avaliação mais precisa seja possível das condições e do regime fluvial.

Os resultados obtidos da disponibilidade hídrica subsidiam a tomada de decisão, no que tange a viabilidade técnica, económica e para a conservação ambiental. Além da compreensão da disponibilidade hídrica de uma localidade ser essencial para o gerenciamento dos recursos hídricos. 


\section{REFERÊNCIAS}

ABRAPCH. Associação Brasileira de PCHs e CGHs. O que são PCH's e CGH's. Disponível em: <https://abrapch.org.br/o-setor/o-que-sao-pchs-e-cghs/>. Acesso em: 12 mar. 2021.

ANA. Agência Nacional de Águas e Saneamento Básico. Outorga e Fiscalização. Brasília: ANA, 2021. Disponível em: <https://www.ana.gov.br/gestao-da-agua/outorga-e-fiscalizacao>. Acesso em: 12 mar. 2021.

ANA. Agência Nacional de Águas e Saneamento Básico. HIDROWEB v3.2.6 - Séries Históricas de Estações. Brasília: ANA, 2021. Disponível em: 〈http://www.snirh.gov.br/hidroweb/serieshistoricas>. Acesso em: 12 mar. 2021.

BACCI, D. C.; PATACA, E. M. Educação para a água. R. Estudos Avançados, v. 22. n. 63, p. 211226, 2008.

BELICO, J. C. B. et al. Comparação entre vazões mínimas de referência para o rio Formoso - MG. R. Enciclopédia Biosfera, Goiânia. v. 9, n. 17, p. 718-733, 2013.

BENETTI, A. D.; LANNA, A. E.; COBALCHINI, M. S. Metodologias para determinação de vazões ecológicas em rios. R. Brasileira de Recursos Hídricos, Porto Alegre. v. 8, n. 2, p. 149-160, 2003.

BRASIL. Decreto $n^{\circ}$ 99.274, de 6 de junho de 1990. Regulamenta a lei $n^{\circ} 6.902$, de 27 de abril de 1981 e a Lei ${ }^{\circ}$ 6.938, de 31 de agosto de 1981, que dispõem, respectivamente obre a criação de Estações Ecológicas e Áreas de Proteção Ambiental e sobre a Política Nacional do Meio Ambiente, e dá outras providências. Diário Oficial da República Federativa do Brasil, Poder Executivo, Brasília, DF, 7 jun. 1990. Seção 1.

BRASIL. Resolução CONAMA n ${ }^{\circ}$ 357/2005, de 17 de março de 2005. Dispõe sobre a classificação dos corpos de água e diretrizes ambientais para o seu enquadramento, bem como estabelece as condições e padrões de lançamento de efluentes, e dá outras providências. Diário Oficial da República Federativa do Brasil, Poder Executivo, Brasília, DF, 30 jul. 2005.

BRASIL. Resolução CONAMA, n 237/1997, de 19 de dezembro de 1997. Dispõe sobre a revisão e complementação dos procedimentos e critérios utilizados para o licenciamento ambiental. Diário Oficial da República Federativa do Brasil, Poder Executivo, Brasília, DF, 22 dez. 1997. Seção 1.

CAMPOS, S. R. M.; SILVA, V. P. A efetividade do estudo de impacto ambiental e do licenciamento em projetos de usinas hidrelétricas. R. Caminhos de Geografia, Uberlândia. v. 13, n. 41, 2012.

FERNANDES, G. S. Centrais Geradoras Hidrelétricas: uma análise procedimental de sua aprovação e a viabilidade. 65f. Trabalho de Conclusão (Bacharel em Engenharia Civil) - Instituto Federal de Educação, Ciência e Tecnologia de Goiás, Goiânia, 2019. Disponível em: <http://repositorio.ifg.edu.br/handle/prefix/357>. Acesso em: 14 mar. 2021.

GERIBELLO, D. F. Hidrelétricas no início do século XX: tratadística e periódicos. R. Labor e Engenho, Campinas. v. 9, n. 1, p. 82-92, 2015.

IBAMA. Instituto Brasileiro do Meio Ambiente e dos Recursos Naturais Renováveis. Resolução n ${ }^{\circ}$ 141/2012, de 10 de julho de 2012. Diário Oficial da União, Brasília, DF, 2012. Disponível em: 
<https://www.ibama.gov.br/component/legislacao/?view=legislacao\&legislacao=127789>. Acesso em: 16 mar. 2021.

IBGE. Instituto Brasileiro de Geografia e Estatística. IBGE Cidades. Rio de Janeiro: IBGE, 2010. Disponível em: <https://cidades.ibge.gov.br/brasil/pr/santa-maria-do-oeste/panorama>. Acesso em: 17 mar. 2021.

IBGE. Instituto Brasileiro de Geografia e Estatística. IBGE Cidades. Rio de Janeiro: IBGE, 2020. Disponível em: <https://cidades.ibge.gov.br/brasil/pr/santa-maria-do-oeste/panorama>. Acesso em: 17 mar. 2021.

IAT. Instituto Água e Terra. Atlas de recursos hídricos do Estado do Paraná. Curitiba: IAT, 2021. Disponível em: <www.iat.pr.gov.br/Pagina/Atlas-de-Recursos-Hidricos-do-Estado-do-Parana\#>. Acesso em: 18 mar. 2021.

IAT. Instituto Água e Terra. Bacia do Rio Piquiri e Paraná II. Curitiba: IAT, 2010. Disponível em: <http://www.iat.pr.gov.br/sites/agua-terra/arquivos_restritos/files/documento/2020-07/piquiri.pdf>. Acesso em: 16 mar. 2021.

IAT. Instituo Água e Terra. Estações de monitoramento GEO. Curitiba: IAT, 2021. Disponível em: <http://www.geoem.pr.gov.br/geoem/pages/templates/initial_public.jsf?windowld=dcd>. Acesso em: 16 mar. 2021.

PARANÁ. Lei Estadual n 12.726, de 26 de novembro de 1999. Lei do Sistema Estadual deRecursos Hídricos: Institui a Política Estadual de Recursos Hídricos e cria o Sistema Estadual de Gerenciamentos de Recursos Hídricos do Paraná. Curitiba: Assembleia Legislativa do Estado do Paraná, 26 nov. 1999. 14p.

SisCAH. Sistema Computacional para Análises Hidrológicas. Grupo de pesquisas em recursos hídricos - softwares. SisCAH. 1.0. Disponível em: < http://www.gprh.ufv.br/?area=softwares>. Acesso em: 15 jan. 2021.

TUCCI, C. E. M. Regionalização de Vazões no Rio Grande do Sul. Porto Alegre: IPH/UFRGS, 1991. Disponível em: http://lume.ufrgs.br/bitstream/handle/10183/192875/000017201.pdf?sequence=1>. Acesso em: 14 mar. 2021.

VESTENA, L. R.; DIAS-OLIVEIRA, E.; CUNHA, M. C.; THOMAZ, E. L. Vazão ecológica e disponibilidade hídrica na bacia das Pedras, Guarapuava-PR. R. Ambiente e Água, Taubaté. v. 7, n. 3, p. 212-227, 2012. 